\title{
Article \\ Experimental and Numerical Study of Lattice Girder Composite Slabs with Monolithic Joint
}

\author{
Xuefeng Zhang ${ }^{1}$, Huiming $\mathrm{Li}^{1}{ }^{1}$, Shixue Liang ${ }^{2, *} \mathbb{C}$ and Hao Zhang ${ }^{1}$ \\ 1 College of Civil Engineering, Zhejiang University of Technology, Hangzhou 310014, China; \\ xuefeng_zhang@126.com (X.Z.); zjslhm1996@126.com (H.L.); zhanghao@zjut.edu.cn (H.Z.) \\ 2 School of Civil Engineering and Architecture, Zhejiang Sci-Tech University, Hangzhou 310018, China \\ * Correspondence: liangsx@zstu.edu.cn
}

check for updates

Citation: Zhang, X.; Li, H.; Liang, S.; Zhang, H. Experimental and Numerical Study of Lattice Girder Composite Slabs with Monolithic Joint. Crystals 2021, 11, 219. https:// doi.org/10.3390/cryst11020219

Academic Editor: Yifeng Ling

Received: 3 February 2021

Accepted: 18 February 2021

Published: 23 February 2021

Publisher's Note: MDPI stays neutral with regard to jurisdictional claims in published maps and institutional affiliations.

Copyright: (c) 2021 by the authors. Licensee MDPI, Basel, Switzerland. This article is an open access article distributed under the terms and conditions of the Creative Commons Attribution (CC BY) license (https:// creativecommons.org/licenses/by/ $4.0 /)$.

\begin{abstract}
This paper studies the behavior of lattice girder composite slabs with monolithic joint under bending. A full-scale experiment is performed to investigate the overall bending resistance, deflection and the final crack distribution of latticed girder composite slab under uniformly distributed load. A finite element model is given for the analysis of the latticed girder composite slabs. The effectiveness and correctness of the numerical simulations are verified against experimental results. The experimental and numerical studies conclude that the lattice girder composite slabs conform to the requirement of existing design codes. A parametric study is provided to investigate the effects of lattice girder with following conclusions: (a) the lattice girder significantly increases the stiffness of the slab when comparing with the precast slab without reinforcement crossing the interface; (b) the additional reinforcement near the joint slightly increases the stiffness and resistance, while it prevents damage near the joint.
\end{abstract}

Keywords: precast concrete structure; lattice girder semi-precast slabs; bending resistance; FE modelling; concrete damage

\section{Introduction}

Among various types of components in the precast concrete structures, slabs are particularly suitable and achievable for precasting since the loads on slabs are usually uniform and their shapes are regular. As a result, precast and composite slabs have been used for concrete structures for more than 200 million $\mathrm{m}^{2}$ in China, 2018. It is also predicted that in the coming 5 years, the usage of precast slabs will expand to 2 billion $\mathrm{m}^{2}$ in China, which will bring about CNY 600 billion to the construction market. According to the construction demands and economic considerations, it is of great interest in studying the experiments and numerical simulations of the precast concrete slabs.

One of the most widely used precast floors is the latticed girder composite slab (LGCS) system. As depicted in Figure 1, it consists of steel lattice girders which are cast with the precast plank, and cast-in-place concrete is poured after the installation of precast plank. It combines the cast-in-place and precast slab to utilize the advantages of both forms which increases construction efficiency, quality control and construction savings. In addition, since the precast and cast-in-place planks are fully continuous and tied together without the need for shuttering on site, they show better connecting behaviors when comparing with total precast concrete slabs.

In order to investigate the mechanical behavior of composite slabs, a number of experimental studies [1-5] have been provided for the flexural bearing capacity, shear strength, bonding assessment and interface behaviors of precast planks without reinforcement crossing the interface. Meanwhile, the existence of latticed girder resists the interface shear force and avoids slippage, delamination and debonding at the interface. Some experimental studies have been conducted on the mechanical behavior of LGCS. Du et al. [6] provided an experimental work on the flexural bearing capacity of lattice girder composite slabs. 
Newell and Goggins [7] carried out experiments of the lattice girder composite slabs at construction stage and examined the key parameters which influence their behavior at both serviceability and ultimate bearing limit states.

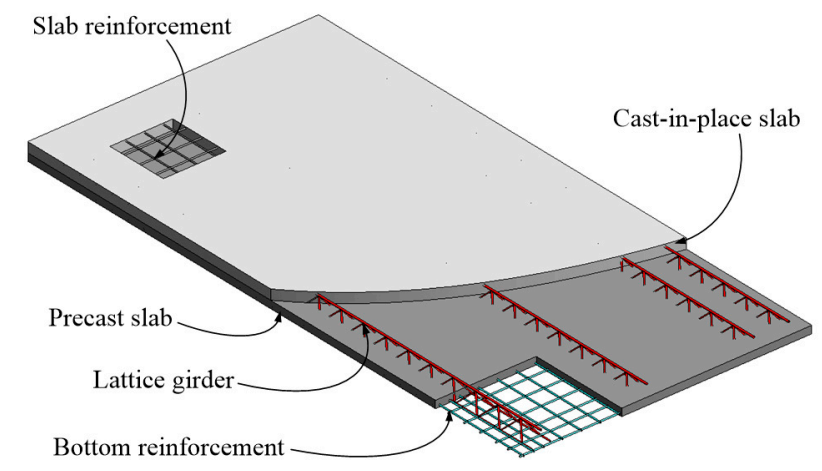

Figure 1. Latticed girder composite slabs (LGCS).

As for the numerical modeling of the precast concrete structures, two kinds of numerical models are developed, namely the macro level element models and three-dimensional (3D) solid finite element (FE) models. In the first kind models, the fiber elements are adopted to simulate the beams and columns [8-10], and layered shell are utilized to simulate the precast slabs [11,12]. It is obvious that the macro level element models is simple and computationally efficient. Nevertheless, the macro level element models cannot precisely simulate the latticed girder and the contact between precast and cast-in-place concrete. Models of the second kind are 3D solid finite element models, which can provide simulations of the local region and detailed set up of RC structures [13-15]. Thanks to the development of computational speed, 3D finite element modelling provides the promising results in the numerical analysis of precast concrete structures, due to its ability to describe the complex connection behavior in an elaborate manner.

Based on the aforementioned background, the aim of this paper is to experimentally and numerically investigate mechanical properties of LGCS under bending. Full-scale experiment of LGCS with monolithic joint under uniformly distributed load is carried out to obtain the load-deflection curve, strain distribution of concrete and reinforcement and the crack distribution of the bottom surface of the slab. It is shown in the experimental results, the mechanical properties of latticed girder composite slab completely satisfy the design criterion under bearing capacity limit state. Furthermore, the safety of the slab can also be achieved under the load of 2.5 times of bearing capacity limit states. In order to thoroughly analysis the mechanical behavior of latticed girder composite slabs, a 3D FE model by ABAQUS is provided, with a particular emphasis on the bending behavior and damage of the slab. In the FE model, the nonlinear material behavior of the steel and concrete all both considered, and all components in contact with the concrete are properly modeled. The proposed FE model is validated by the experimental results of several indexes, such as load-deflection curve, reinforcement strain, final crack width, etc. Then, a parametric study is performed to quantify the influence of the lattice girder and additional reinforcement. It is concluded that: (a) the lattice girder provides stiffness and the bonding between precast plank and cast-in-place concrete; (b) the additional reinforcement has no evident influence on the stiffness of the slab, but it helps preventing the damage of concrete near the joint.

\section{Experimental Study}

\subsection{Test Specimen}

A full-scale experiment is undertaken on LGSC with monolithic joint in the Engineering Research Center of Precast Concrete of Zhejiang Province, Hanzhou, China. According to the layout of the frame structure in the engineering applications, the whole slab is 
supported by reinforced beams on 4 sides (Figure 2). Four columns are settled at the corner of the beams and the bottom of the columns are rigidly connected to the ground. In the experiment, $x$ direction is used to represent the direction along the slab, namely parallel to the monolithic joint direction, and y direction is used to represent the direction vertical to the monolithic joint direction. In this experiment, the size of specimen is $5.0 \mathrm{~m} \times 5.0 \mathrm{~m}$ (measured from the axis of beams). Many precast factories require supports at a maximum of $2.4 \mathrm{~m}$ to limit deflection during transportation. The whole slab is composed by 2 precast planks with the size of $2.31 \mathrm{~m} \times 4.62 \mathrm{~m}$ and this is chosen so that the limitation of supports can be fulfilled. As depicted in Figure 2, the precast bottom plank of the whole slab is composed by 2 precast concrete lattice girder planks. Therefore, one monolithic joint (Figure 2) is settled between precast concrete lattice girder planks.

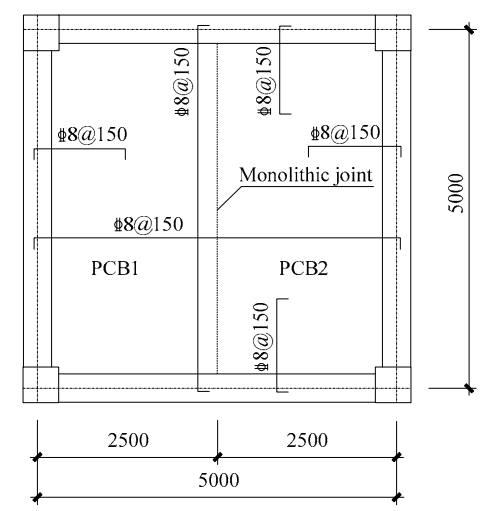

Figure 2. Layout plan of LGCS.

The thickness of precast bottom plank is chosen as $60 \mathrm{~mm}$, and the thickness of the cast-in-place top plank is $80 \mathrm{~mm}$ [16]. The beams and columns are cast-in-place, where the strength of precast bottom plank and cast-in-place top plank are both C30 and the steel bars are all made of HRB400. The reinforcement in these two precast planks is C 8 at $150 \mathrm{~mm}$ (C $8 @ 150)$ spacing in both the longitudinal and transverse directions and the concrete cover to the reinforcement at the plank bottom surface is $25 \mathrm{~mm}$. Reinforcement is settled near the support as C 8 at $150 \mathrm{~mm}$ (C 8@150). It is shown in Figure 3, four latticed girders are settled in one precast bottom plank (PCB1). The first lattice girder is placed $140 \mathrm{~mm}$ from the joint, which is equal to thickness of the slab. The second lattice girder placed $280 \mathrm{~mm}$ from the first lattice girder. These two lattice girders are arranged to strengthen the joint. A lattice girder is settled in the middle region of the precast plank at intervals of $850 \mathrm{~mm}$ from the second lattice girder. The last lattice girder is placed $200 \mathrm{~mm}$ from the joint to the beam to enhance the beam-slab connection.

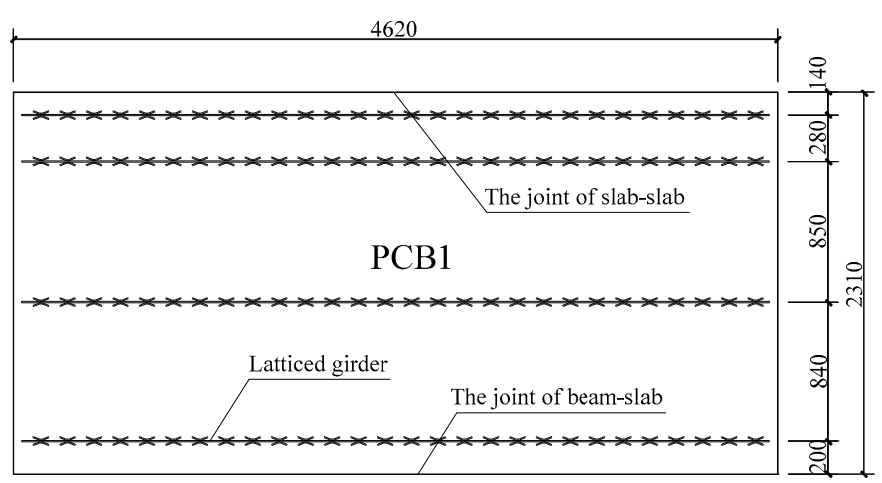

Figure 3. Latticed girder of precast bottom plank. 
The configuration of latticed girder is illustrated in Figure 4. The detailed latticed girder and monolithic joint are shown in Figure 5. In order to further enhance the resistance of the slab near monolithic joint, additional reinforcement with C 10@130 is arranged along the joint. The length of the additional reinforcement is $970 \mathrm{~mm}$ (Figure 5). As shown in Figure 6, reinforcement near the support is installed to strengthen the connection between slab and beam. The length of the support reinforcement is $120 \mathrm{~mm}$. It is emphasized that the design parameters, such as size, thickness and reinforcement of the slab, are strictly followed "Code for Design of Concrete Structures (GB50010-2010) [17]" and "Technical Specification for Application of Lattice Girder Slab (T/CECS 715-2020) [16]".

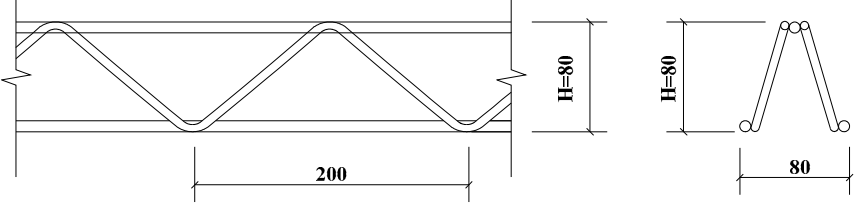

Figure 4. Configuration of latticed girder (elevational and sectional drawing).

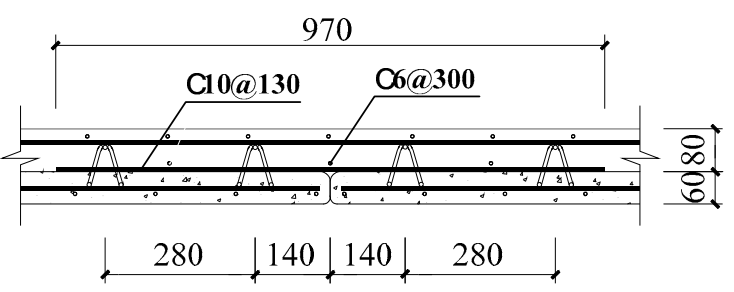

Figure 5. Monolithic joint.

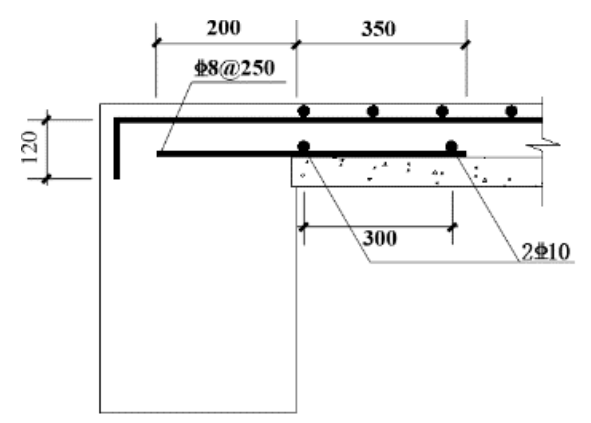

Figure 6. Beam-slab connection.

\subsection{Testing Method}

In order to investigate the strain condition of different components in the LGCS, electrical resistance (ER) strain gauges are bonded to the longitudinal reinforcement and the concrete surface of the slab. The arrangement of strain measuring point of concrete is illustrated in Figure 7a. It can be seen in Figure 7a that $\mathrm{C} 1 \mathrm{a}$ and $\mathrm{C} 1 \mathrm{~b}$ are symmetrically arranged. In the experiment, the strain is calculated as the mean value of $\mathrm{C} 1 \mathrm{a}$ and $\mathrm{C} 1 \mathrm{~b}$, the remaining strain measuring points are the same. Since lattice girder and longitudinal reinforcement are both set in the slab, the strain distribution is much complex than that of cast-in-place slab. We apply 13 strain measuring point of bottom slab longitudinal reinforcement depicted in Figure $7 \mathrm{~b}$, and the final strain is also calculated as the mean value of S1a and S1b. With regard to the adopted instrumentation, five linear variable differential transformers in Figure 7c are applied to measure the vertical displacement at midspan, in the middle of each precast plank and at edge of the bottom slab. With regard to the adopted instrumentation, five linear variable differential transformers in Figure $7 \mathrm{c}$ are applied to measure the vertical displacement at midspan, in the middle of each precast plank and at edge of the bottom slab. 


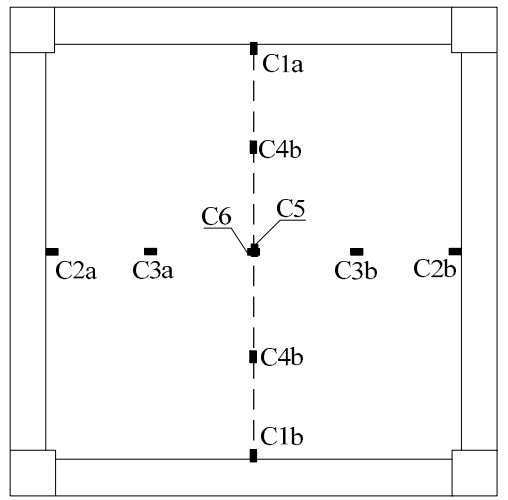

(a)

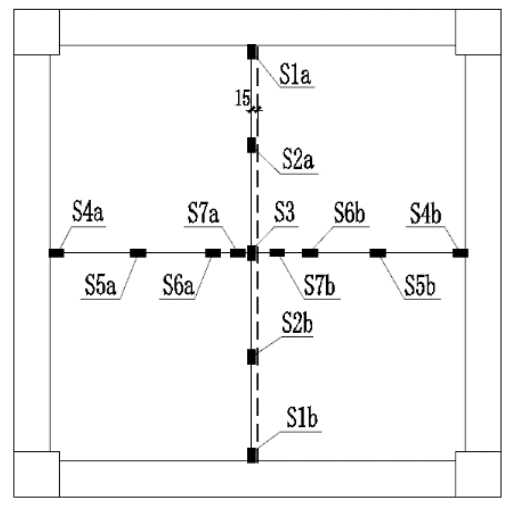

(b)

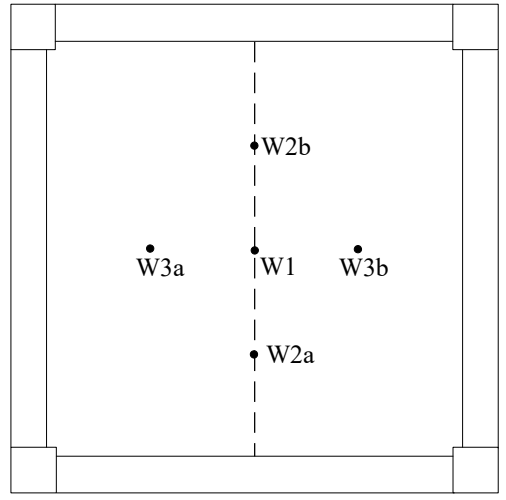

(c)

Figure 7. Arrangement of testing measuring points: (a) Strain measuring points of concrete; (b) Strain measuring points of steel; (c) Deflection measuring point.

The loading scheme is carried out with reference to the "Chinese Standard for Testing Methods of Concrete Structures (GB/T 50152-2012) [18]". A uniformly distributed load is applied by pile loading of sandbags in Figure 8 . The serviceability limit state is calculated as $8.4 \mathrm{kN} / \mathrm{m}^{2}$ and the bearing capacity limit state is calculated as $16.4 \mathrm{kN} / \mathrm{m}^{2}$ [17]. In order to investigate the ultimate bearing capacity of the composite slab in this study, the maximum value of the uniformly distributed load is chosen as $40 \mathrm{kN} / \mathrm{m}^{2}$, which is corresponding to 2.5 times of the value of ultimate bearing capacity of the slab. Before the maximum distributed load $\left(40 \mathrm{kN} / \mathrm{m}^{2}\right)$, the loading procedure (including the weight of the slab and pile loading) is applied progressively by steps, and for each step the load is $2.0 \mathrm{kN} / \mathrm{m}^{2}$. When the sandbags are piled up, they are distributed evenly to avoid arch effect. It should be noted that for each loading step, sandbags are evenly piled to the slab by forklift. After each loading step, the load should be kept for 15 min until the measured stress, strain and deflection are stable.

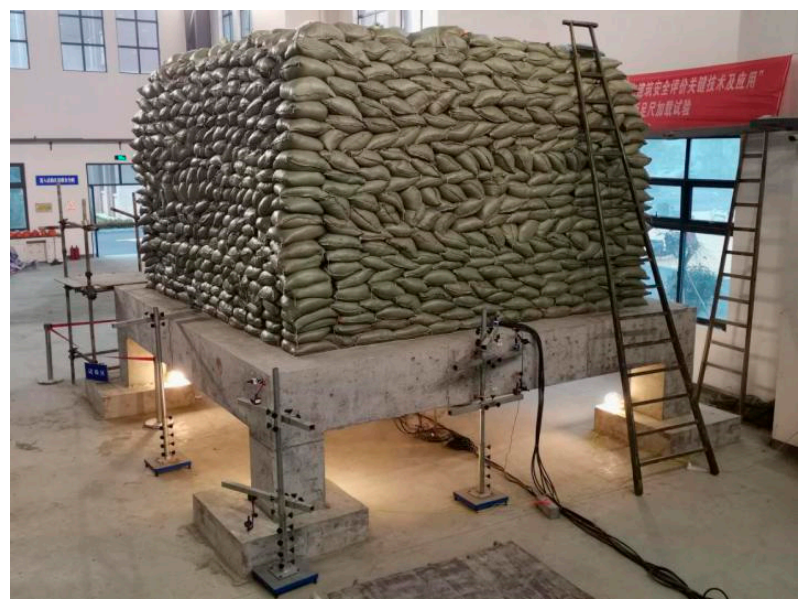

Figure 8. Pile loading of the slab.

\subsection{Test Results}

During the entire loading process of the slab, the crack development of the slab is carefully observed and monitored. The crack distribution at different loading stages is shown in Figure 9. No visible crack is observed under the serviceability limit state $\left(8.4 \mathrm{kN} / \mathrm{m}^{2}\right)$, which satisfy the crack width limit $0.2 \mathrm{~mm}$ of the design code [17]. When the slab is loaded to $10 \mathrm{kN} / \mathrm{m}^{2}$, the first crack appears in the midspan of the precast bottom plank at $45^{\circ}$, which width is recorded as $0.06 \mathrm{~mm}$. After loaded to $10 \mathrm{kN} / \mathrm{m}^{2}$, the existing cracks in the midspan of the precast bottom plank gradually extend and pass 
through the monolithic joint. With further increase of load, the cracks in the precast bottom plank continue to increase, and gradually develop towards the direction of $45^{\circ}$. It is also observed that some paralleled cracks developed near the main crack. Finally, when the load reaches $40 \mathrm{kN} / \mathrm{m}^{2}$, the maximum width of the crack at the precast bottom plank is $0.76 \mathrm{~mm}$, located at the joint, and the maximum width of the crack at the joint is $0.10 \mathrm{~mm}$. Under the maximum loading value of this test is $40 \mathrm{kN} / \mathrm{m}^{2}$, which is about 2.5 times of the design value of bearing capacity, the crack width of the LGCS does not reach the crack width limit of $1.50 \mathrm{~mm}$ corresponding to the bearing capacity limit, and no shear failure is observed near the joint.

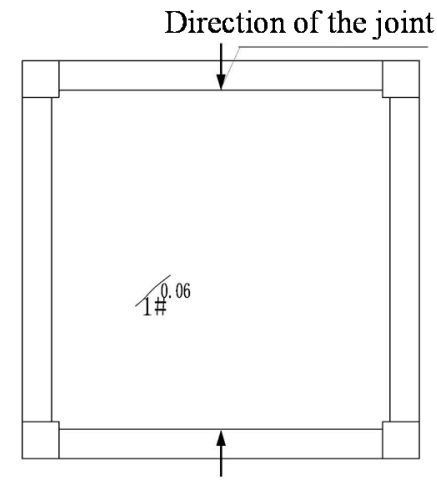

(a)

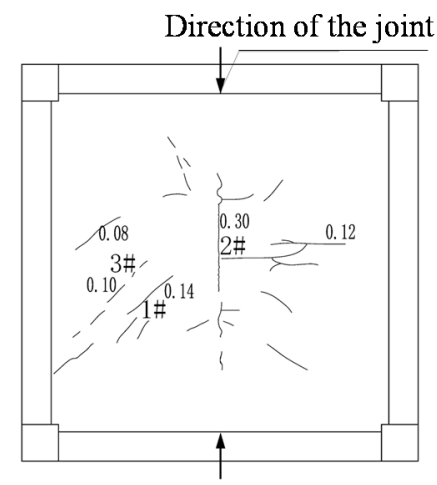

(d)

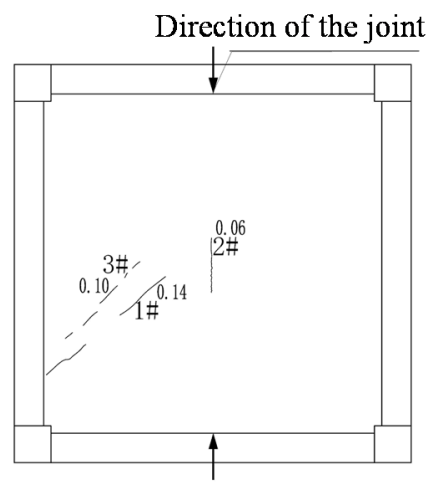

(b)

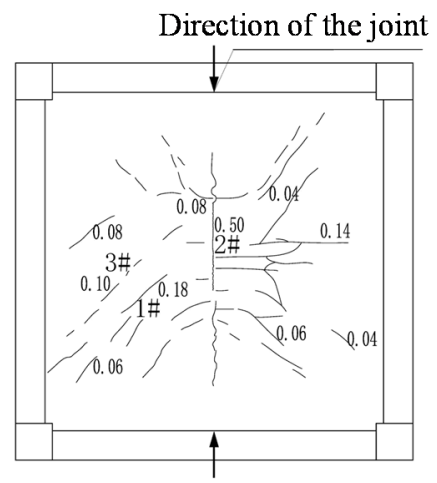

(e)

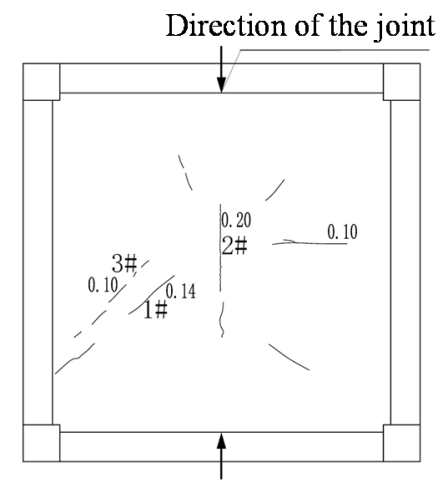

(c)

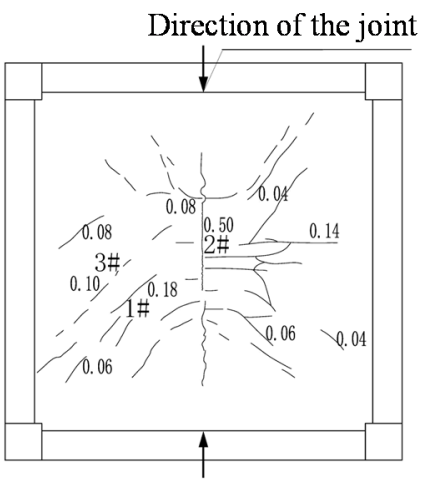

(f)

Figure 9. Cracking distribution of bottom plank at different loading stages: (a) Crack distribution at load q = $10 \mathrm{kN} / \mathrm{m}^{2}$; (b) Crack distribution at load $\mathrm{q}=16 \mathrm{kN} / \mathrm{m}^{2}$; (c) Crack distribution at load $\mathrm{q}=22 \mathrm{kN} / \mathrm{m}^{2}$; (d) Crack distribution at load $\mathrm{q}=28 \mathrm{kN} / \mathrm{m}^{2} ;$ (e) Crack distribution at load $\mathrm{q}=34 \mathrm{kN} / \mathrm{m}^{2} ;(\mathbf{f})$ Crack distribution at load $\mathrm{q}=40 \mathrm{kN} / \mathrm{m}^{2}$.

Before the distributed load of composite plate reaches $10 \mathrm{kN} / \mathrm{m}^{2}$, the deflection increases linearly with the load. The lattice girder slab is a hybrid system and, therefore, its initial stiffness is due to the composite action between the lattice girders, concrete and reinforcement. When cracking in the concrete plank progressively occurs, there is a load redistribution and stiffness degradation. At this stage, the strength of concrete decreases and the stiffness of the slab is primarily provided by the lattice girder and the reinforcement. When loaded to the ultimate state at $40 \mathrm{kN} / \mathrm{m}^{2}$, the midspan deflection of the bottom slab reaches $24.07 \mathrm{~mm}$, which is about $1 / 208$ of the span of the slab. However, the deflection is far below the limit of the maximum deflection (1/50 of the span of the slab) according to the Code for Design of Concrete Structures (GB50010-2010) [17]. The load-deflection curve of the latticed girder composite slab is depicted in Figure 10. In this figure, W1 curve represents the load-deflection curve of the midspan from measuring point W1 in Figure 7. W2 and W3 curves represent the mean load-deflection curves of W2a and W2b, W3a and $\mathrm{W} 3 \mathrm{~b}$, respectively. In this test, the deflections of $\mathrm{x}$ direction and $\mathrm{y}$ direction are basically the same in the whole process, indicating that the LGCS has compatible deformation capability. 
Under the uniformly distributed load, the vertical deformation of the slab is similar to that of the traditional concrete two-way slab.

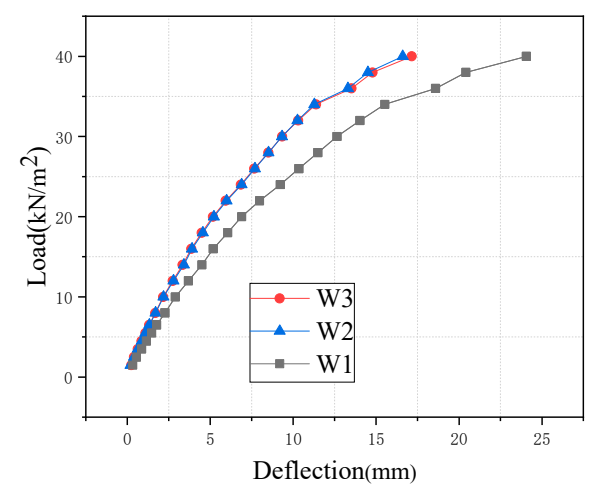

Figure 10. Load-deflection curve.

It can be concluded from both the crack distribution and the load-deflection curve that the design of LGCS meets the requirement of existing design provisions. Admittedly, the safety and serviceability of LGCS under uniformly distributed load can be achieved. However, the crack width and deflection of LGCS is relatively small, even under 2.5 times design value of bearing capacity, which reflect conservative design of LGCS.

According to the ER strain gauges at the bottom plank of concrete, the strain distribution of the concrete can be recorded. It can be seen from Figure 11 that the tensile strain $\varepsilon_{x}$ of concrete which parallels to the joint is greater than that $\varepsilon_{y}$ in the vertical direction after reaches $7.5 \mathrm{kN} / \mathrm{m}^{2}$, which indicates that the slab presents a certain mechanical characteristic of orthogonal anisotropic due to the existence of monolithic joint.

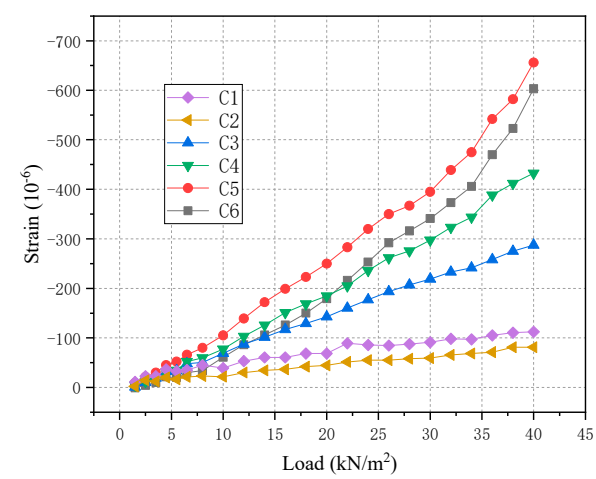

Figure 11. Load-strain curves of concrete at bottom plank.

Figure 12a,b show the load-strain curves of bottom longitudinal reinforcement which are parallel and vertical to monolithic joint, respectively. As for the reinforcement parallel to the joint, it can be seen from that the reinforcement strain is small before loading to $16 \mathrm{kN} / \mathrm{m}^{2}$. After being loaded to $16 \mathrm{kN} / \mathrm{m}^{2}$, the strains from all measuring points paralleled to joint increases progressively, and their value exceed that of vertical to joint. The maximum strain value appears in the midspan. As for the reinforcement vertical to the joint, similar strain distribution can also be observed. The load-strain curves of the vertical longitudinal reinforcement are more irregular when comparing with that of paralleled longitudinal reinforcement, probably due to the existence of the joint which cuts off the steel bars and brings the discontinuities. 


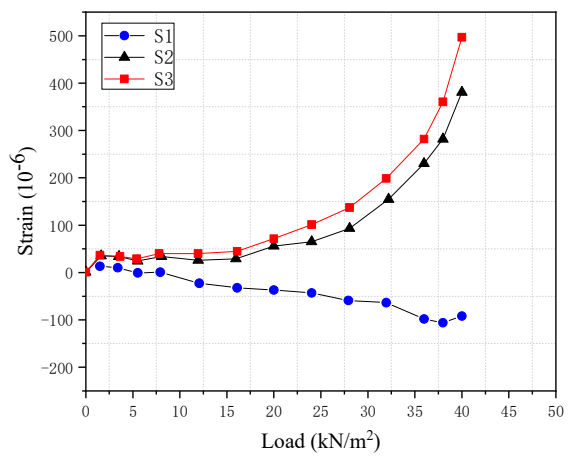

(a)

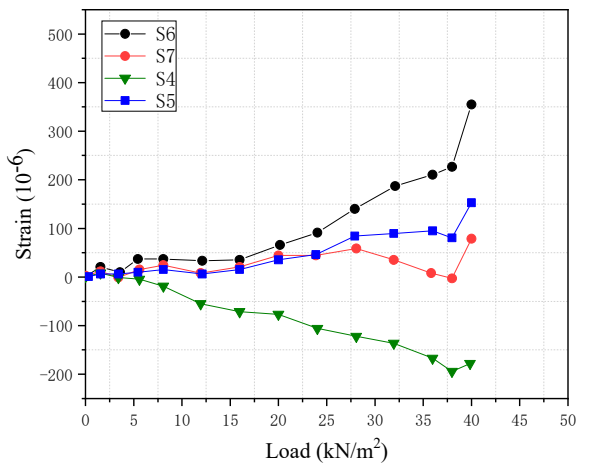

(b)

Figure 12. Load-strain curves of reinforcement: (a) Load-strain curves paralleled to the joint; (b) Load-strain curves vertical to the joint.

\section{Numerical Simulation}

\subsection{Numerical Model}

In this study, a finite element (FE) model based on ABAQUS [19] is established to investigate the behavior of the latticed girder composite slab. The main components affecting the behavior of latticed girder composite slab are the thickness of the precast and cast-in-place slab, the set-up of latticed girder, and the material properties. In addition, to obtain accurate results from the FE analysis, the contact between precast slab and castin-place slab must be properly modelled. Therefore, the nonlinearities, such as contacts between slabs and material properties are considered in the FE models.

As for the steel material modeling, the von Mises criterion is adopted, where the option ( ${ }^{*}$ PLASTIC) in ABAQUS used in association with the plastic flow rule. In the plastic model of ABAQUS, the steel material behavior is initially elastic with Young's modulus $E_{s}$ followed by strain hardening and then by the yielding criterion. In the modeling, the Young's modulus of steel is chosen as $E_{s}=2 \times 10^{5} \mathrm{MPa}$ and the Poisson's ratio is $v=0.3$. The yield strength of steel is chosen as $f_{y, r}=400 \mathrm{Mpa}$ and the ultimate strength is $f_{s t, r}=540 \mathrm{MPa}$. In the FE analysis of ABAQUS [19], the uniaxial behavior of the steel in can be automatically transformed into a multiaxial stress state.

When comparing with the steel, concrete exhibits complex nonlinear properties, such as stiffness degradation, lateral effect and strain softening. In this study, concrete damage plastic (CDP) [20] model is used to represent the mechanical property of concrete. In CDP model, the stiffness degradation which is represented by damage variables and constitutive relations, can be decoupled from the plastic evolution equations. Two damage variables, namely tensile damage and compressive damage, account for the different stiffness degradation states. The constitutive equations for elastoplastic responses are established from the degradation damage response. To control the evolution of the yield surface, the effective stress function is applied, so that the material parameters can be conveniently calibrated. In the application of CDP model, the stress-strain law and damage law are thoroughly studied and discussed [21,22].

Under the framework of the plastic damage model, the total strain can be divided as

$$
\begin{gathered}
\varepsilon=\varepsilon^{e}+\varepsilon^{p} \\
\varepsilon^{e}=E^{-1}: \sigma
\end{gathered}
$$

where $E$ is the elastic stiffness tensor; $\varepsilon^{e}$ is the elastic strain and $\varepsilon^{p}$ is the inelastic strain.

The constitutive relationship can be attributed as

$$
\sigma=E_{0}:\left(\varepsilon-\varepsilon^{p}\right)
$$




$$
\begin{aligned}
\varepsilon^{\cdot p} & =\lambda \cdot \nabla_{\sigma} \Phi(\sigma) \\
\kappa & =\lambda \cdot H(\sigma, \kappa)
\end{aligned}
$$

where $\sigma$ is the effective stress; $\boldsymbol{E}_{0}$ is the initial elastic stiffness tensor with $\boldsymbol{E}=(1-D) \boldsymbol{E}_{0}$; $\lambda$ is a nonnegative function referred to as the plastic consistency parameter; $\Phi$ is a scalar plastic potential function; $\kappa$ is the damage variable tensor which can be the compressive damage variable $d_{c}$ and tensile damage variable $d_{t}$ in the scalar damage model; $\mathbf{H}$ is the damage evolution function.

For uniaxial tension and compression, the following stress-strain law can be defined as

$$
\begin{aligned}
\sigma_{t} & =\left(1-d_{t}\right) E_{0} \varepsilon \\
\sigma_{\mathcal{c}} & =\left(1-d_{c}\right) E_{0} \varepsilon
\end{aligned}
$$

In this study, we adopt the suggested damage law of concrete by Code for Design of Concrete Structures (GB50010-2010/2015) [17]. Under uniaxial compression, the damage law is given as

$$
\begin{aligned}
& d_{c}=\left\{\begin{array}{cc}
1-\frac{\rho_{c} n}{n-1+x_{c}^{n}} & x_{c} \leq 1 \\
1-\frac{\rho_{c}}{\alpha_{c}\left(x_{c}-1\right)^{2}+x_{c}} & x_{c}>1
\end{array}\right. \\
& \rho_{c}=\frac{f_{c r}}{E_{0} \varepsilon_{c r}} \\
& n=\frac{E_{0} \varepsilon_{c r}}{E_{0} \varepsilon_{c r}-f_{c r}} \\
& x_{c}=\frac{\varepsilon}{\varepsilon_{c r}}
\end{aligned}
$$

where $E_{0}$ is the Young's modulus of concrete; $\alpha_{c}$ is the concrete compressive damage curve shape parameter; $f_{c r}$ is the ultimate compressive strength of concrete; $\varepsilon_{c r}$ is the strain corresponding to the ultimate compressive strength $f_{c r}$.

Under uniaxial tension, the tensile damage law is given as

$$
\begin{gathered}
d_{t}=\left\{\begin{array}{cc}
1-\rho_{t}\left(1.2-0.2 x_{t}^{5}\right) & x_{t} \leq 1 \\
1-\frac{\rho_{t}}{\alpha_{t}\left(x_{t}-1\right)^{1.7}+x_{t}} & x_{t}>1
\end{array}\right. \\
x_{t}=\frac{\varepsilon}{\varepsilon_{t r}} \\
\rho_{t}=\frac{f_{t r}}{E_{0} \varepsilon_{t r}}
\end{gathered}
$$

where $\alpha_{t}$ is the concrete tensile damage curve shape parameter; $f_{t r}$ is the ultimate tensile strength of concrete; $\varepsilon_{t r}$ is the strain corresponding to the ultimate compressive strength $f_{t r}$.

In this modeling, we choose the concrete material value as: $E_{0}=2.55 \times 10^{4} \mathrm{MPa}$; $f_{c r}=26.8 \mathrm{MPa} ; \varepsilon_{c r}=1.64 \times 10^{-3} ; \alpha_{c}=1.36 ; f_{t r}=2.15 \mathrm{MPa} ; \varepsilon_{t r}=1.02 \times 10^{-4} ; \alpha_{t}=1.51$. In the application of ABAQUS [19], the following parameters should be determined for the CDP model given Table 1.

Table 1. Parameter value of CDP.

\begin{tabular}{ccccc}
\hline Dilation Angle & Eccentricity & $f_{b_{0}} / f_{c_{0}}$ & $k$ & Viscosity Parameter \\
\hline 30 & 0.1 & 1.16 & 0.667 & 0.0005 \\
\hline
\end{tabular}

The concrete is the modelled by eight-node solid FE (C3D8R) in ABAQUS. Additionally, the reinforcement is modelled by Truss Element in ABAQUS. To avoid numerical inaccuracies, the shape of the C3D8R satisfies the limits and aspect ratio as recommended by ABAQUS [19]. The mesh size of the composite plate is selected as 
$100 \mathrm{~mm} \times 100 \mathrm{~mm} \times 20 \mathrm{~mm}$ (length $\times$ width $\times$ depth). To model the loading process of the slab, the distributed load is applied on the top surface of the slab. The boundary condition of the composite plate is set as four side fixed support.

To obtain accurate results from the FE analyses, all components in contact with the concrete must be properly modelled. There are two surfaces of interaction: (a) the precast concrete plank and cast-in-place concrete interface; (b) the contacts between concrete and reinforcement, including the latticed girder and longitudinal reinforcement. As for interaction (a), a surface-to-surface contact is chosen, where normal behavior and tangential behavior were considered. Therefore, the default contact option in ABAQUS [19] is utilized. This default contact option consists of a hard contact pressure-over closure relationship. Regarding the tangential direction, the penalty frictional formulation with a friction coefficient equal to 0.3 is employed. When it comes to the interaction (b), the fully coupled contact between reinforcement and concrete is adopted and the embedded region in ABAQUS is used in the simulation.

\subsection{Simulation Results}

Figure 13a,b depict the maximum principal stress of the concrete and reinforcement stress at the bottom of the slab, respectively. It can be seen that the overall stress distribution of slab shows the strong characteristics of two-way slab, and the reinforcement stress near the support and mid-span of the slab is relatively large. It is found that a region of additional reinforcement near the joint has smaller stress value when comparing with the neighboring region. This is probably due to the arrangement of additional reinforcement near the joint.

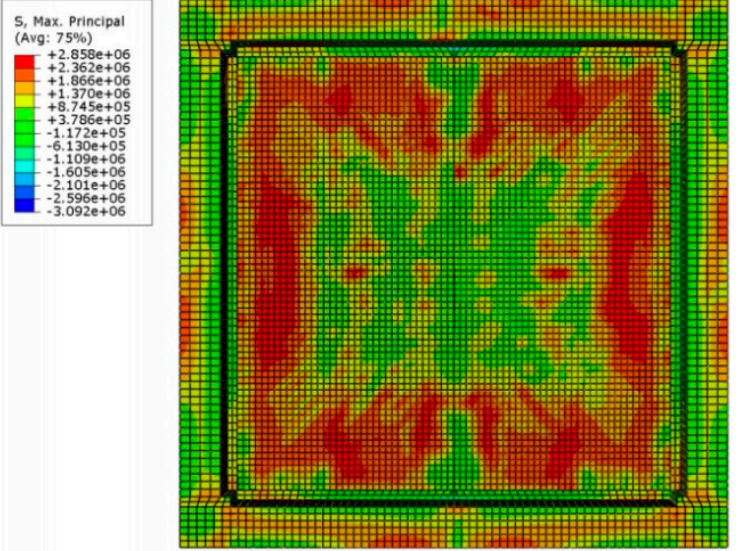

(a)

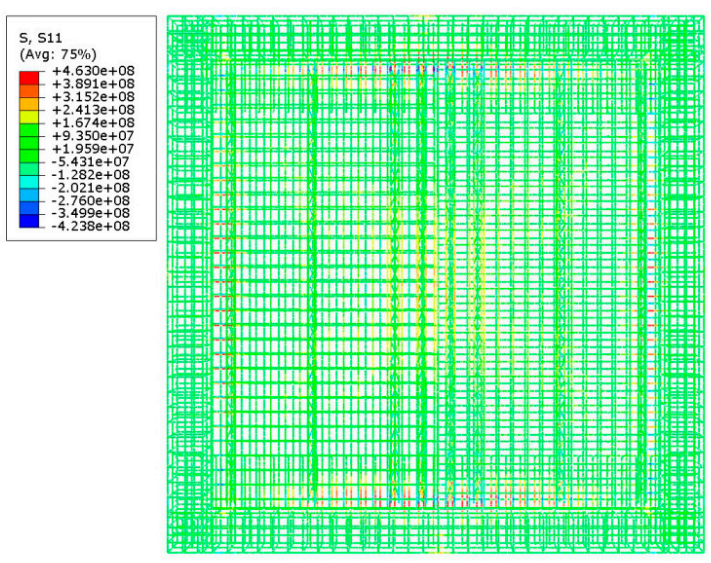

(b)

Figure 13. (a) Maximum principal stress of slab bottom concrete; (b) Reinforcement Stress of slab.

Figure 14 demonstrates the simulation results of load-strain curves concrete at bottom plank. As shown, the numerical curves are compared to the experimental results, where numerical results show satisfactory accuracy within the band corresponding to the experimental results, verifying the reliability of the proposed numerical model. The detailed comparison between numerical and experimental results are given in Table 2. As proposed in Table 2, the maximum error is $7.6 \%$, which further indicates accurate simulation results. The midspan load-deflection curve of the composite slab shows the deformation development under the load. Figure 15 demonstrates the comparison between the simulation results and the test results of the load-deflection curve of the mid-span of the composite slab. The simulated maximum deflection of the midspan is $25.13 \mathrm{~mm}$, and the experimental maximum deflection is $24.07 \mathrm{~mm}$. The result is in agreement with the experimental result, which testify correctness and effectiveness of the proposed numerical model. 


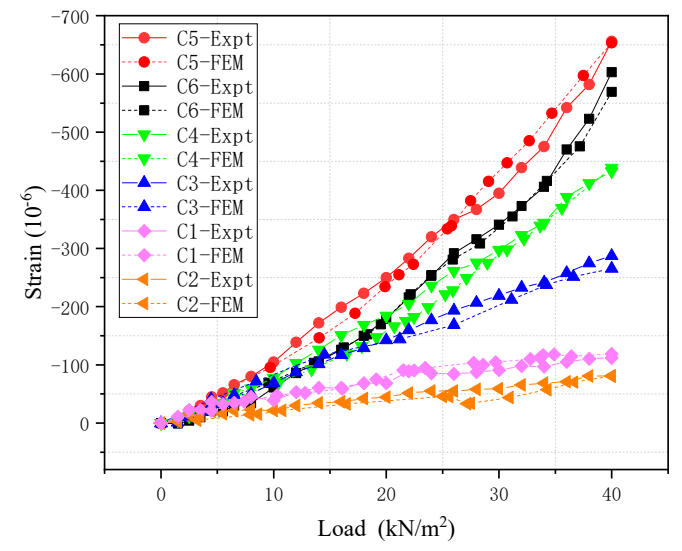

Figure 14. Simulation of concrete strain.

Table 2. Comparison of simulation and experimental value of concrete strain

\begin{tabular}{lcccccc}
\hline Strain/(10-6) & C1 & C2 & C3 & C4 & C5 & C6 \\
\hline Experiment & 112 & 81 & 287 & 432 & 656 & 603 \\
Simulation & 118 & 80 & 265 & 438 & 653 & 569 \\
$\quad$ Error & $5.4 \%$ & $-1.2 \%$ & $-7.6 \%$ & $1.4 \%$ & $-0.4 \%$ & $-5.6 \%$ \\
\hline
\end{tabular}

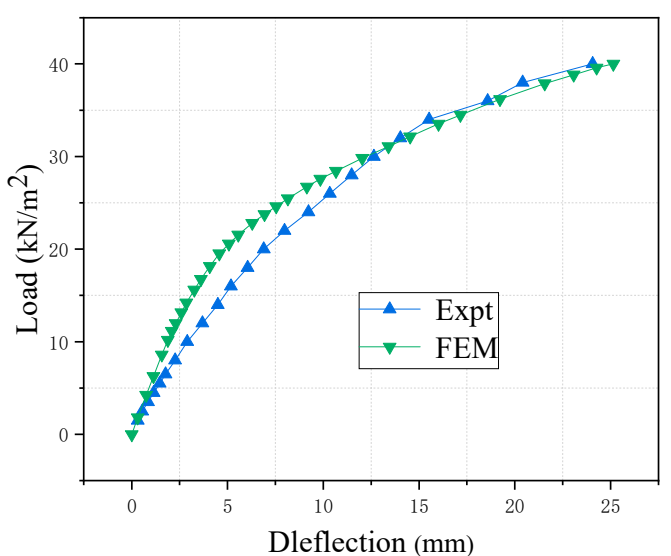

Figure 15. Load-deflection of the test and simulation.

Apart from the bearing capacity and deformation of the concrete structure, the investigations of concrete cracking, including crack spacing and crack width, is also important in the numerical simulation of concrete structure. To estimate the crack spacing and the crack width of simple concrete components, empirical equations had been proposed in some design codes such as Code for Design of Concrete Structures (GB50010-2010) [17]. When it comes to the RC structure with complex reinforcement and loading status, the estimations of crack spacing and crack should rely on numerical methods. In the past decades, several advanced numerical models had been put forward to simulate the cracking process of concrete, ranging from cohesive elements [23,24], element-free methods [25-27] to extended finite element method (XFEM) $[28,29]$. Admittedly, these numerical methods provided relatively accurate ways to simulate and evaluate the cracks of concrete. However, for the finite element modelling of real structure, which usually contains huge amount elements, the aforementioned numerical methods might bring undesirable computational costs. In the continuum damage models of concrete, the damage variables, the tensile and compressive damage variables, are adopted to represent the tensile and compressive damage mechanisms which brought by the development of cracks. Therefore, the damage vari- 
ables could partially represent the cracking status without the introduction of additional numerical costs.

The interface between precast and cast-in-place concrete is the weak zone of the composite slab. The bonding in this interface is mainly provided by the chemical adhesive force, interfacial friction, mechanical interaction and the resistance brought by lattice girder, which contains complex mechanisms. Observing the concrete damage at this interface is conducive to determining whether full composite action up to the ultimate loading capacity without interface failure can be achieved. The bottom surface of the precast plank is also intriguing in the simulation that the cracks at bottom surface might induce the leaks and the reinforcement corrosion. Since the cracks in the concrete is usually brought by the tension, the tensile damage of the interface and bottom surface are shown in Figures 16 and 17b. As demonstrated in Figures 16 and 17b, the tensile damage distribution reveals a typical crack pattern of the two-way slab. However, it can be seen from Figure 16 that the damage value is relatively small in the region where additional reinforcement is settled near the joint. This numerical result in Figure $17 \mathrm{~b}$ is correspondent to the experimental crack pattern depicted in Figure 9 (Figure 17a).

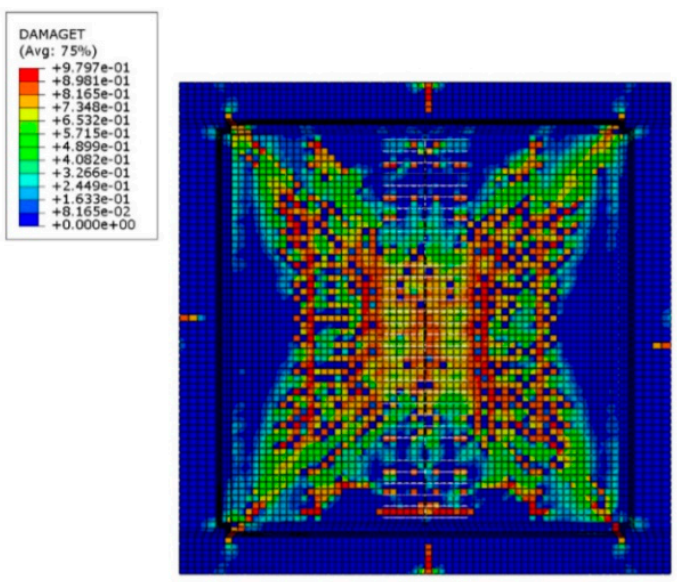

Figure 16. Tensile damage contour at concrete interface.

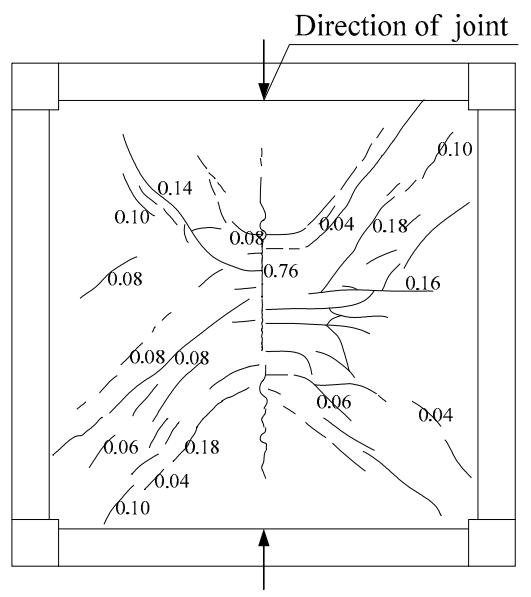

(a)

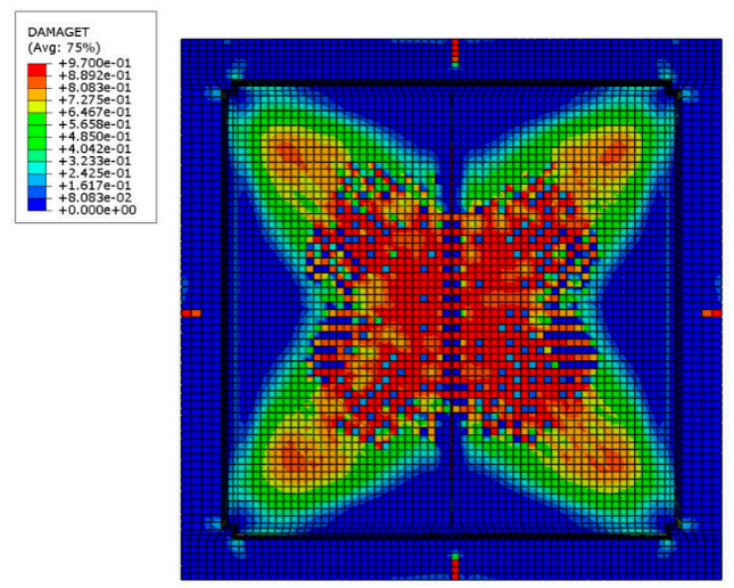

(b)

Figure 17. Comparison of experimental and numerical failure modes at concrete bottom plank: (a) Experimental cracking distribution; (b) Tensile damage contour of concrete bottom plank from FE simulation. 


\section{Parametric Study}

Once the FE model is testified by the experimental tests, a parametric study can be performed by using the aforementioned numerical model of the slab. The parametric simulation analyzes (1) the influence of the lattice girder to the mechanical behavior of slab; (2) the influence of the additional reinforcement near the joint (Figure 5) to the stiffness and load-deflection curve of slab. Three FE models are generated in this parametric study that M1 is the original FE model, M2 is the FE model without additional longitudinal reinforcement and M3 is the FE model without lattice girder. It is emphasized that the material properties, sizes, boundary conditions and the surface contacts are the same in these FE models.

The comparison of load-deflection curves is given in Figure 18. It can be seen in this figure that M1 and M2 curves are similar. As for M2, the maximum deflection is $26.41 \mathrm{~mm}$, which increases $5.1 \%$ compared to the deflection of M1. It is implied that the existence of the additional reinforcement has only slight influence on the resistance and stiffness of the slab. However, the additional reinforcement plays a part in preventing the cracks near joint. Tensile damage distribution of M2 is shown in Figure 19 that the maximum value is bigger than M1 given in Figure 17b. Furthermore, the damage of M2 near the joint is severer than M1 (Figure 17b) with the absence of additional reinforcement.

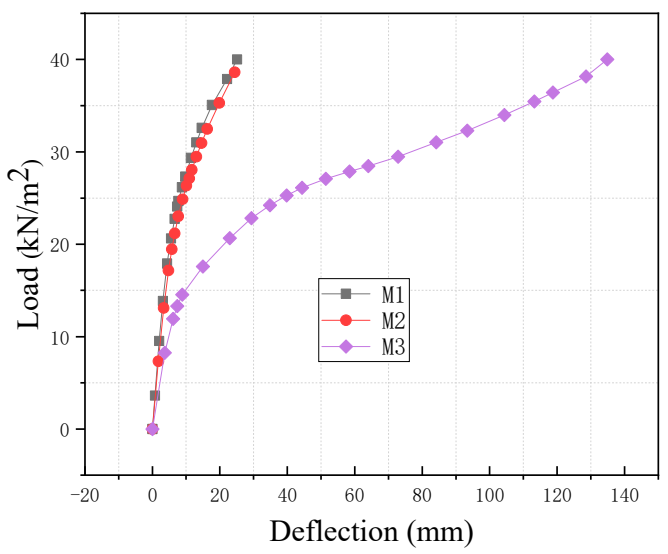

Figure 18. Comparison of load-deflection curves from FE modeling.

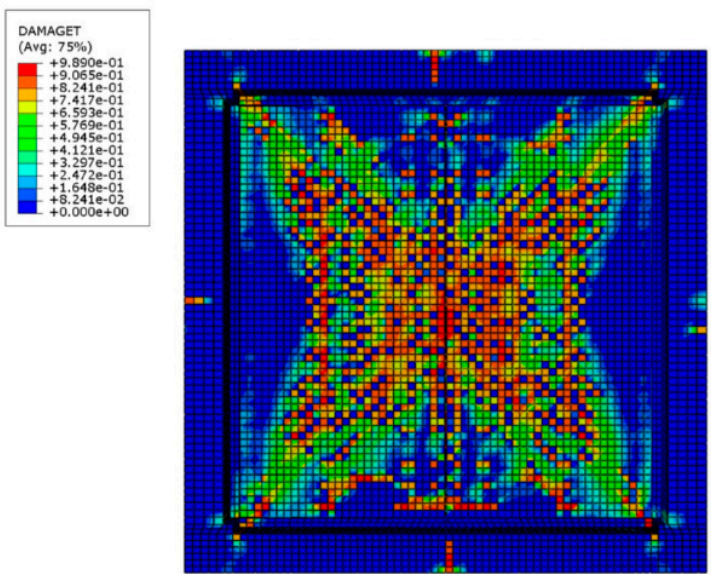

Figure 19. Tensile damage contour of concrete bottom plank from M2 simulation result.

As for M3, the shape of load-deflection curve and maximum deflection in Figure 18 are significantly different from M1 and M2, which indicate a much lower stiffness of the slab without the lattice girder. The maximum deflection of M3 reaches $134.90 \mathrm{~mm}$ (1/37 of the span of the slab), almost 5 times that of M1, which exceeds the limit of the 
maximum deflection (1/50 of the span of the slab) according to the Code for Design of Concrete Structures (GB50010-2010) [17]. Therefore, the existence of the lattice girder plays an essential role in the mechanical behavior of the slab.

\section{Conclusions}

A comprehensive experimental and numerical modelling has been conducted to investigate the structural performance of LGCS. A full-scale experiment is performed to investigate the bending resistance, deflection and the final crack distribution of LGCS under uniformly distributed load. The experimental results are used for the validation of FE models, which were then employed to conduct a series of parametric studies to extend the current test data over a broader range of the influences of lattice girder and additional reinforcement. The main conclusions are summarized below:

(1) Before the distributed load reaches $10 \mathrm{kN} / \mathrm{m}^{2}$, the deflection increases linearly with the load. When cracking in the concrete plank progressively occurs, there is a load redistribution and stiffness degradation. The final midspan deflection LGCS of the bottom slab is $24.07 \mathrm{~mm}$ (about $1 / 208$ of the span) which is far below the limit of the maximum deflection (1/50 of the span of the slab) according to the Code for Design of Concrete Structures (GB50010-2010), under 2.5 times of the bearing capacity limits $\left(40 \mathrm{kN} / \mathrm{m}^{2}\right)$. It also can be observed by the load-deflection curve that the LGCS has sufficient stiffness and bending resistance. Therefore, the LGCS meets the requirement of existing design code $[16,17]$. Experimental test data in the presenting paper can be used to determine the load-deflection of the LGCS that can result in significant efficiencies for propping arrangements on site.

(2) No visible crack is observed under serviceability limit state, which is below the limit of maximum crack width $(0.2 \mathrm{~mm})$ under the design code. The GLCS satisfies the criterion of the serviceability. The final cracks reach to the 4 corners of the slabs along the direction of $45^{\circ}$, which illustrate typical cracking pattern of the two-way slab. Under 2.5 times of the bearing capacity limits $\left(40 \mathrm{kN} / \mathrm{m}^{2}\right)$, the final maximum crack appears at the monolithic joint with the value of $0.76 \mathrm{~mm}$ which is much bigger than the other areas.

(3) An elaborate FE model to simulate the LGCS is presented in this study. From the numerical analyses, it has been demonstrated that the numerical model successfully predict the composite slab's resistance capacity, the load-deflection behavior and the final cracking pattern of the on-site test. The proposed FE model can be applied in the numerical modelling of LGCS in the further precast structural nonlinear analysis.

(4) A parametric study is performed to observe the following conclusions: (a) the existence of lattice girder provides significant stiffness to the slab and helps the precast plank and cast-in-place layer working together; (b) the additional reinforcement to the joint has slight effect on increasing the stiffness of slab, but it prevents the cracks near joint.

Author Contributions: Conceptualization, S.L.; methodology, X.Z. and H.L.; software, X.Z. and H.L.; validation, S.L and H.Z.; writing-original draft preparation, S.L.; writing-review and editing, S.L.; All authors have read and agreed to the published version of the manuscript.

Funding: This research was funded by National Science Foundation of China, grant number 51808499; Science Foundation of Zhejiang Province of China, grant number LGF20E080019.

Data Availability Statement: Data is contained within the article.

Acknowledgments: This study is supported by Engineering Research Centre of Precast Concrete of Zhejiang Province. The help of all members of the Engineering Research Centre is sincerely appreciated. We would also like to express our sincere appreciations to the anonymous referee for valuable suggestions and corrections.

Conflicts of Interest: The authors declare no conflict of interest. 


\section{References}

1. Girhammar, U.A.; Pajari, M. Tests and analysis on shear strength of composite slabs of hollow core units and concrete topping. Constr. Build. Mater. 2008, 22, 1708-1722. [CrossRef]

2. Baran, E. Effects of cast-in-place concrete topping on flexural response of precast concrete hollow-core slabs. Eng. Struct. 2015, 98, 109-117. [CrossRef]

3. Rahimi Mansour, F.; Abu Bakar, S.; Ibrahim, I.S.; Marsono, A.K.; Marabi, B. Flexural performance of a precast concrete slab with steel fiber concrete topping. Constr. Build. Mater. 2015, 75, 112-120. [CrossRef]

4. Ibrahim, I.S.; Elliott, K.S.; Abdullah, R.; Kueh, A.B.H.; Sarbini, N.N. Experimental study on the shear behaviour of precast concrete hollow core slabs with concrete topping. Eng. Struct. 2016, 125, 80-90. [CrossRef]

5. Lam, S.S.E.; Wong, V.; Lee, R.S.M. Bonding assessment of semi-precast slabs subjected to flexural load and differential shrinkage. Eng. Struct. 2019, 187, 25-33. [CrossRef]

6. Du, H.; Hu, X.; Meng, Y.; Han, G.; Guo, K. Study on composite beams with prefabricated steel bar truss concrete slabs and demountable shear connectors. Eng. Struct. 2020, 210, 110419. [CrossRef]

7. Newell, S.; Goggins, J. Experimental study of hybrid precast concrete lattice girder floor at construction stage. Structures 2019, 20, 866-885. [CrossRef]

8. Nahar, M.; Islam, K.; Billah, A.M. Seismic collapse safety assessment of concrete beam-column joints reinforced with different types of shape memory alloy rebars. J. Build. Eng. 2020, 29, 101106. [CrossRef]

9. Yu, J.; Tan, K.H. Numerical analysis with joint model on RC assemblages subjected to progressive collapse. Mag. Concr. Res. 2014, 66, 1201-1218. [CrossRef]

10. Celik, O.C.; Ellingwood, B.R. Modeling Beam-Column Joints in Fragility Assessment of Gravity Load Designed Reinforced Concrete Frames. J. Earthq. Eng. 2008, 12, 357-381. [CrossRef]

11. Abdullah, R.; Samuel Easterling, W. New evaluation and modeling procedure for horizontal shear bond in composite slabs. J. Constr. Steel Res. 2009, 65, 891-899. [CrossRef]

12. Tzaros, K.A.; Mistakidis, E.S.; Perdikaris, P.C. A numerical model based on nonconvex-nonsmooth optimization for the simulation of bending tests on composite slabs with profiled steel sheeting. Eng. Struct. 2010, 32, 843-853. [CrossRef]

13. Ríos, J.D.; Cifuentes, H.; Martínez-De La Concha, A.; Medina-Reguera, F. Numerical modelling of the shear-bond behaviour of composite slabs in four and six-point bending tests. Eng. Struct. 2017, 133, 91-104. [CrossRef]

14. Feng, D.; Wu, G.; Lu, Y. Finite element modelling approach for precast reinforced concrete beam-to-column connections under cyclic loading. Eng. Struct. 2018, 174, 49-66. [CrossRef]

15. Karam, M.S.; Yamamoto, Y.; Nakamura, H.; Miura, T. Numerical Evaluation of the Perfobond (PBL) Shear Connector Subjected to Lateral Pressure Using Coupled Rigid Body Spring Model (RBSM) and Nonlinear Solid Finite Element Method (FEM). Crystals 2020, 10, 743. [CrossRef]

16. Technical Specification for Application of Lattice Girder Slab; T/CECS 715-2020; China Construction Industry Press: Beijing, China, 2020.

17. Code for Design of Concrete Structures; GB50010-2010/2015; China Construction Industry Press: Beijing, China, 2015.

18. Chinese Standard for Testing Methods of Concrete Structures; China Construction Industry Press: Beijing, China, 2012.

19. Abaqus, 6.14; User's Manual; SIMULIA: Providence, RI, USA, 2014.

20. Lee, J.; Fenves, G.L. Plastic-damage model for cyclic loading of concrete structures. J. Eng. Mech. 1998, 124, 892-900. [CrossRef]

21. Kytinou, V.K.; Chalioris, C.E.; Karayannis, C.G. Analysis of Residual Flexural Stiffness of Steel Fiber-Reinforced Concrete Beams with Steel Reinforcement. Materials 2020, 13, 2698. [CrossRef] [PubMed]

22. Sun, Y.; Liu, Y.; Wu, T.; Liu, X.; Lu, H. Numerical Analysis on Flexural Behavior of Steel Fiber-Reinforced LWAC Beams Reinforced with GFRP Bars. Appl. Sci. 2019, 9, 5128. [CrossRef]

23. Xu, X.; Needleman, A. Numerical simulations of fast crack growth in brittle solids. J. Mech. Phys. Solids 1994, 42, 1397-1434. [CrossRef]

24. Camacho, G.T.; Ortiz, M. Computational modelling of impact damage in brittle materials. Int. J. Solids. Struct. 1996, 33, $2899-2938$. [CrossRef]

25. Belytschko, T.; Lu, Y.Y.; Gu, L. Element-free Galerkin methods. Int. J. Numer. Meth. Eng. 1994, 37, 229-256. [CrossRef]

26. Liu, W.K.; Jun, S.; Zhang, Y.F. Reproducing kernel particle methods. Int. J. Numer. Meth. Fluids 1995, 20, 1081-1106. [CrossRef]

27. Chen, J.; Pan, C.; Wu, C.; Liu, W.K. Reproducing kernel particle methods for large deformation analysis of non-linear structures. Comp. Meth. Appl. Mech. Eng. 1996, 139, 195-227. [CrossRef]

28. Sukumar, N.; Moes, N.; Moran, B.; Belytschko, T. Extended finite element method for three-dimensional crack modelling. Int. J. Numer. Meth. Eng. 2000, 48, 1549-1570. [CrossRef]

29. Moes, N.; Belytschko, T. Extended finite element method for cohesive crack growth. Eng. Fract. Mech. 2002, 69, 813-833. [CrossRef] 